\title{
Mutual regulation between DNA-PKcs and snail1 leads to increased genomic instability and aggressive tumor characteristics
}

\author{
B-J Pyun ${ }^{1,4,5}$, HR Seo ${ }^{2,5}$, H-J Lee ${ }^{2}$, YB Jin ${ }^{2}$, E-J Kim², NH Kim ${ }^{3}$, HS Kim³ ${ }^{3}$ HW Nam ${ }^{3}$, Jl Yook ${ }^{\star, 3}$ and Y-S Lee*,1
}

Although the roles of DNA-dependent protein kinase catalytic subunits (DNA-PKcs) in the non-homologous end joining (NHEJ) of DNA repair are well-recognized, the biological mechanisms and regulators by DNA-PKcs besides DNA repair, have not been clearly described. Here, we show that active DNA-PKcs caused by ionizing radiation, phosphorylated Snail1 at serine (Ser) 100, led to increased Snail1 stability. Furthermore, phosphorylated Snail1 at Ser100 reciprocally inhibited the kinase activity of DNAPKcs, resulting in an inhibition of DNA repair activity. Moreover, Snail1 phosphorylation by DNA-PKcs was involved in genomic instability and aggressive tumor characteristics. Our results describe novel cellular mechanisms that affect genomic instability, sensitivity to DNA-damaging agents, and the migration of tumor cells by reciprocal regulation between DNA-PKcs and Snail1. Cell Death and Disease (2013) 4, e517; doi:10.1038/cddis.2013.43; published online 28 February 2013

Subject Category: Cancer

DNA double-strand breaks (DSBs) arise from normal cellular processes as well as exogenous sources, such as ionizing radiation (IR) or other forms of genotoxic stress. Homologous recombination (HR) and non-homologous end joining (NHEJ) are the two major pathways for the repair of DNA DSBs. NHEJ is the predominant repair pathway for DSBs induced by IR. DNA-dependent protein kinase (DNA-PK) is important in the regulation of NHEJ, as demonstrated by the hypersensitivity of DNA-PK catalytic subunit (DNA-PKcs) $-/-$ mice to IR and high levels of unrepaired DSBs observed in DNA-PKcs - Imice after exposure to other genotoxic agents. ${ }^{1}$

The formation of DNA-PK complex by Ku70/80 and DNAPKcs, requires simultaneous binding of these enzymes to a DNA terminus. ${ }^{2,3}$ After introduction of a DSB, the DNA-PKcs enzyme is recruited rapidly to the DNA-Ku scaffold. The serine/threonine kinase activity of DNA-PKcs is not activated until the DNA-PKcs molecule is associated with the Ku70/80 heterodimer and a DNA terminus. Many targets for DNAPKcs, as a protein kinase, have been identified in vitro, including XRCC4, Ku70/80, Artemis, p53, and even DNAPKcs. ${ }^{1,4,5}$ However, the biological function of DNA-PKmediated phosphorylation remains unclear.

The E-box-binding transcription factor, Snail1, functions as a potent inducer of the mesenchymal transition and invasive phenotype of epithelial cells. Although Snail1 was first described as a key regulator of the epithelial-mesenchymal transition (EMT) during development and in the progression of cancer, recent studies suggest that the aberrant expression of Snail1 is also involved in apoptotic resistance to various genotoxic agents including IR, as well as the acquisition of a stem cell phenotype. ${ }^{6-8}$ Although recent evidence suggest that Snail1 participates in both the EMT process and in the resistance to genotoxic stress, the molecular network of Snail1 in the DNA repair process has not yet been identified.

In a preliminary study, one of the proteins that interacts with Snail1 was identified as DNA-PKcs. In this study, we demonstrated that a direct interaction between DNA-PKcs and Snail1 induced phosphorylation of Snail1 at serine (Ser) 100 , resulting in Snail functional activity. We further showed that DNA-PKcs-mediated phosphorylation of Snail1 blocked the DSB repair process by inhibiting the catalytic activity of DNA-PKcs. The reciprocal regulation between DNA-PKcs and Snail1 was critical for defective DNA repair activity, which affected genomic instability and the migration of tumor cells.

\section{Results}

Snail1 interacted with DNA-PKcs. Our preliminary study suggested that proteins that interact with Snail1 included DNA-PKcs (Supplementary Figure S1). To characterize the interaction between Snail1 and DNA-PKcs, we first detected the expression patterns of Snail1 and DNA-PKcs in human cancer tissues. The co-expression of these two proteins was found in the colon (total 40 cases) and lung (total 40 cases)

\footnotetext{
${ }^{1}$ College of Pharmacy, Division of Life and Pharmaceutical Sciences, Ewha Womans University, Seoul, Korea; ${ }^{2}$ Division of Radiation Effects, Korea Institute of Radiological and Medical Sciences, Seoul, Korea; ${ }^{3}$ Department of Oral Pathology, College of Dentistry Yonsei University, Seoul, Korea and ${ }^{4}$ Korean Medicine-Based Herbal Drug Research Group, Herbal Medicine Research Division, Korea Institute of Oriental Medicine (KIOM), Daejeon, Korea

*Corresponding author: Y-S Lee, College of Pharmacy, Division of Life and Pharmaceutical Sciences, Ewha Womans University, 11-1 Daehyun-Dong, Seodaemun-Gu, Seoul 120-750, Korea. Tel: + 8223277 3022; Fax: + 8223277 2851; E-mail: yslee0425@ewha.ac.kr

or JI Yook, Department of Oral Pathology, College of Dentistry Yonsei University, Seoul 120-752, Korea. Tel: + 8222228 3032; Fax: +82 2 392 2952;

E-mail: jiyook@yuhs.ac

${ }^{5}$ These authors contributed equally to this work.

Keywords: DNA-PKcs; reciprocal regulation; snail1; DNA repair; snail1 phosphorylation

Abbreviations: $\mathrm{CHX}$, cycloheximide; DNA-PKcs, DNA-dependent protein kinase catalytic subunits; DSB, double-strand breaks; EMF, epithelial-mesenchymal transition; GSK3 $\beta$, glycogen synthase kinase 3 beta; HR, homologous recombination; IR, ionizing radiation; NHEJ, non-homologous end joining

Received 6.12.12; revised 25.1.13; accepted 28.1.13; Edited by A Stephanou
} 
cancer tissues. However, these were rarely detected in nonneoplastic tissues (Supplementary Figure S2). We also examined the interaction after transfection of Snail1-Flag in MCF7 cells using immunoprecipitation (IP). Interaction of Snail1-Flag with DNA-PKcs was observed in this system (Figure 1a). An IP and an in vitro translation assay using $\mathrm{NCl}$ $\mathrm{H} 460$ cells showed the direct interaction between Snail 1 and DNA-PKcs (Figure 1b). The binding sites of Snail1 that interact with DNA-PKcs were amino acids 8-35 (Figure 1c, left). The binding sequences of DNA-PKcs that interact with Snail1 were amino acids 3534-4129 of the kinase domain (Figure 1c, right). When we examined the endogenous binding activity of these proteins in A549 and NCl-H460 cells that showed relatively high expression of the Snail1 protein in comparison with other cell lines (data not shown), IR exposure simultaneously increased Snail1 protein expression and Snail1 binding activity with DNA-PKcs, however, Si-Snail1 treatment of these cells showed reversed effects (Figure 1d).

DNA-PKcs phosphorylated Snail1 at Ser100 by their direct interaction. As DNA-PKcs phosphorylates SQ/TQ sites, ${ }^{1,9-11}$ we examined the Snail1 sequences in detail and found that Snail1 has one SQ/TQ site at Ser 100 (Supplementary Figure S3). IP with an anti-SQ/TQ antibody and immunoblotting (IB) with anti-Snail1 antibody demonstrated that phosphorylation of Snail1 at the SQ/TQ site occurred in MCF7 cells overexpressing Snail1, and treatment of cells with Si-DNA-PKcs blocked this phosphorylation (Figure 2a, left). When we examined Ser100 phosphorylation of Snail1 using specific antibody directed against phosphopeptides, Si-DNA-PKcs treatment inhibited Snail1 phosporylation at Ser100 in DLD cells. However, GSK-3 $\beta$ was reported to phosphorylate Snail1 at Ser104 and 107, ${ }^{12}$ but did not affect phosphorylation of Snail at Ser 100(Figure 2a, middle). Addition of purified human recombinant DNA-PKcsGST protein to DLD-1 cell lysates induced Snail1 phosphorylation at Ser100 (Figure 2a, right). We found kinase activity of DNA-PKcs in $\mathrm{NCl}-\mathrm{H} 460$ cells using two types of biotinlabeled peptides as substrates; one peptide contained amino acids $96-103$ of Snail 1 that has the SQ/TQ site (PeptA) and the other contained amino acids 103-109 of Snail1 that does not contain the SQ/TQ site (PeptB), but does contain GSK$3 \beta$ phosphorylation sites. A higher level of kinase activity of DNA-PKcs occurred when PeptA was used as a substrate, similar to kinase activity when a positive control of p53 peptide was used as a substrate. However, when PeptB was used as a substrate, kinase activity of DNA-PKcs was not induced, similar to Si-DNA-PKcs-treated cells (Figure $2 b$, left). When we examined these effects using wild-type (WT) (M059K) or DNA-PKcs mutant (M059J) cells, similar effects were observed (Figure 2b, right). IR exposure to $\mathrm{NCl}-\mathrm{H} 460$ cells also induced DNA-PKcs kinase activity when p53 peptide or PeptA were used as substrates, whereas the substrate PeptB did not induce DNA-PKcs kinase activity (Figure 2c).

Snail1 phosphorylation at Ser100 by DNA-PKcs increased its protein stability. As phosphorylation status regulates protein stability, we determined whether
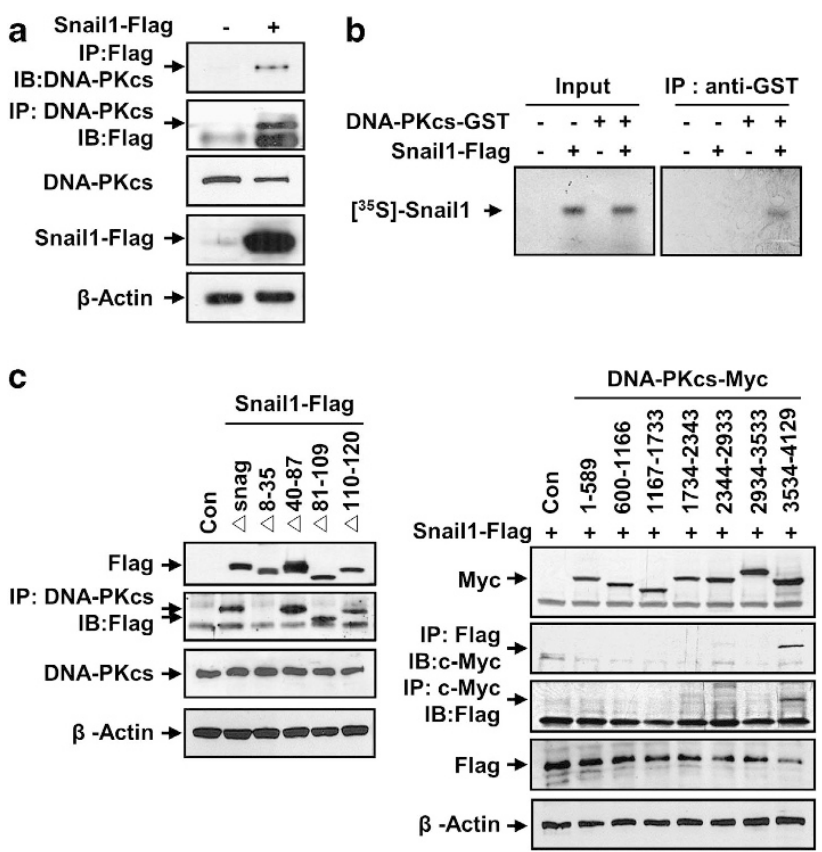

d

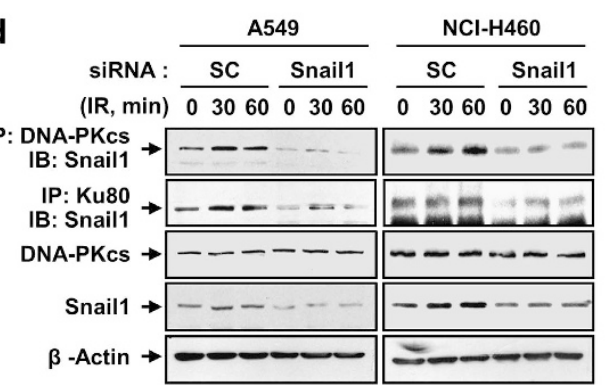

Figure 1 Snail1 interacted with DNA-PKcs. (a) Western blotting or IB was performed following IP using cell extracts after transfection of Snail-Flag to MCF7 cells. (b) In vitro translated L- $\left[{ }^{35} \mathrm{~S}\right]$ - methionine-labeled Snail1 was incubated with GST-DNA-PKcs $(2 \mu \mathrm{g})$ and immunoprecipitates were subjected to an in vitro binding assay using $\mathrm{NCl}-\mathrm{H} 460$ cells. Autoradiogram of L- $\left[{ }^{35} \mathrm{~S}\right]$-methionine-labeled proteins (left) and autoradiogram of ${ }^{35} \mathrm{~S}$-labeled proteins immunoprecipitated with anti-GST antibody (right). (c) Various deletion constructs of Flag-tagged Snail1 and Myctagged DNA-PKCs constructs were transfected into NCl-H460 cells. Western blotting or IB was performed following IP using cell extracts. (d) Western blotting or IB of A549 cells and $\mathrm{NCl}-\mathrm{H} 460$ cell extracts was conducted at the indicated time points following treatment of cells with an IR dose of $5 \mathrm{~Gy}$. The results represent one of three independent experiments

phosphorylation of Snail1 at Ser100 affected Snail1 protein stability. The use of cycloheximide $(\mathrm{CHX})$ to block protein synthesis demonstrated that Si-DNA-PKcs inhibited Snail1 protein stability in $\mathrm{NCl}-\mathrm{H} 460$ cells (Figure $3 a$ ). When the halflife of proteins containing substitutions at Ser100 (S100A and S100D) after treatment with $\mathrm{CHX}$ was examined, the phospho-mimic form of Snail1 at Ser100 (S100D) increased the protein's half-life compared with a phospho-defective mutant of Snail1 at Ser100 (S100A; Figure 3b). This indicates that DNA-PKcs-mediated Snail1 phosphorylation at Ser100 increased the half-life of the Snail1 protein. As Snail 1 is tightly regulated by the ubiquitin proteasome pathway, ${ }^{10}$ we examined Snail1 ubiquitination patterns. 

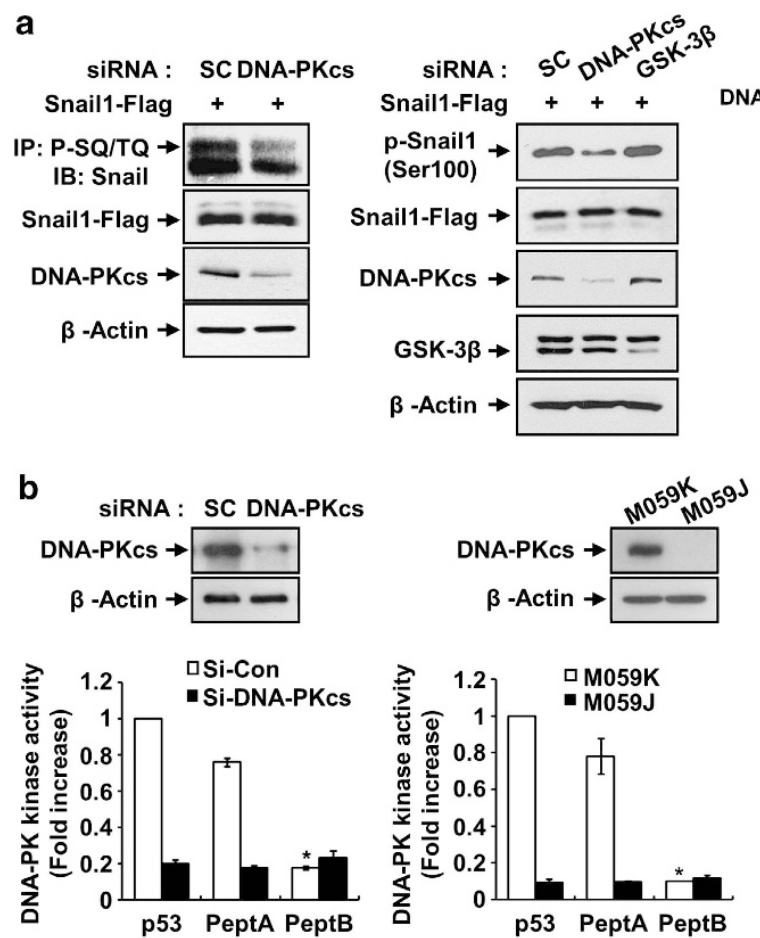

DNA-PKcs-GST(ng/ml) 01050100
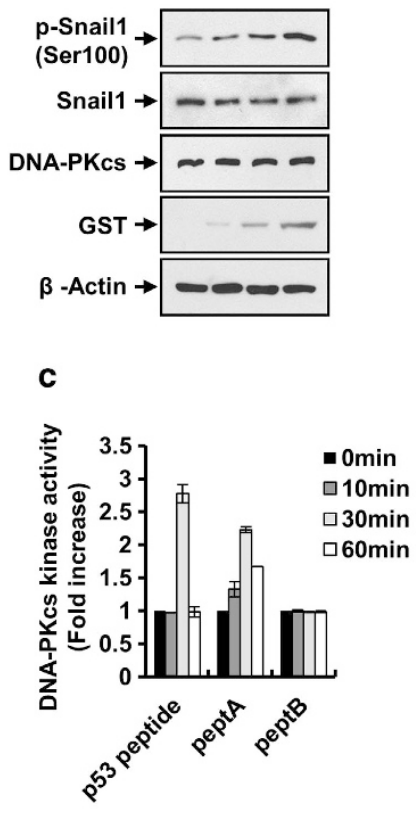

Figure 2 DNA-PKcs-phosphorylated Snail1 at Ser100 by their direct interaction. (a) Scrambled control (SC) and DNA-PKcs (Si-DNA-PKcs) Si-RNAs were transfected into Snail-Flag transfected MCF7 cells and western blotting or IB was conducted following IP on cell extracts (left). SC, Si-DNA-PKcs, or GSK-3 $\beta$ (Si-GSK-3 $\beta$ ) Si-RNAs were transfected into WT-Snail1-overexpressed DLD-1 cells (middle) or purified recombinant DNA-PKcs-GST proteins (0,10,50, and $100 \mathrm{ng} / \mathrm{ml}$ ) were added to DLD-1 cells (right). Lysates were prepared and IB was performed. (b) SC and Si-DNA-PKcs were transfected into NCl-H460 cells. An in vitro DNA-PKcs kinase assay was carried out using biotinylated p53 peptide, peptide A (PeptA, a peptide containing amino acids 96-103 of Snail1, which has the SQ/TQ site), or peptide B (PeptB, a peptide containing amino acids 103-109 of Snail1, which does not contain the SQ/TQ site) (left). An in vitro DNA-PKcs kinase assay was also carried out using M059K and MO59J cells (right). The SAM membrane or $3 \mathrm{~mm}$ filter disc was analyzed using a phosphoimager system and values of Si-Con using p53 peptide as a substrate were set to 1 ( $n=3$, data are presented as means \pm S.D.). * Significantly different from corresponding DNA-PKcs kinase activity using p53 peptide as a substrate at $P<0.05$. (c) In vitro DNA-PKcs kinase assays using $\mathrm{NCl}-\mathrm{H} 460$ cells were performed at the indicated time points following treatment with a dose of $5 \mathrm{~Gy} I \mathrm{R}$. The SAM membrane or $3 \mathrm{~mm}$ filter disc was analyzed using a phosphoimager system and values of the control were set to 1

Similar to the half-life data, Snail1 ubiquitination was increased more by Snail1-S100A (S100A) than Snail1-WT, but in the case of Snail1-S100D (S100D), ubiquitinated Snail1 was completely inhibited (Figure 3c).

To determine whether the protein stability of Snail 1 after phosphorylation at Ser100 affected Snail1 function, E-cadherin promoter activity was examined. E-cadherin promoter activity was not inhibited by Snail1-S100A, whereas in the case of Snail1-S100D, inhibition of E-cadherin activity was still present as with Snail1-WT (Figure $3 d$ and Supplementary Figure S4a). A cell migration assay was then performed to ascertain whether the modulation of E-cadherin activity by Snail1-S100A leads to morphological changes; Snail1-mediated cell migration was inhibited by Snail1-S100A, whereas Snail1-S100D and Snail1-WT increased cell migration (Figure $3 e$ and Supplementary Figure S4a). As Snail1 function is necessary for tumor metastases and expansion, ${ }^{13}$ we examined whether Snail1 phosphorylation at Ser100 affected Snail1-mediated growth of lung metastases. Stable transfection with Snail1-WT, Snail1-S100A, or Snail1-S100D to murine CT26 colon carcinoma cells was performed and these cells were injected into mice to generate lung metastases. ${ }^{13,14}$ Compared with untransfected CT26 cells, Snail1WT overexpression to CT26 cells did not increase lung metastasis assessed by lung weights and tumor-nodule counts in lung tissues. Interestingly, Snail1-S100D showed similar levels of lung metastasis with that of Snail1-WT, however, in the case of Snail-S100A, it significantly inhibited lung metastasis assessed by both lung weights and lung tumor-nodule counts (Figure $3 f$ and Supplementary Figure S4b).

Kinase activity of DNA-PKcs was inhibited by phosphoSnail1 at Ser100. The kinase activity of DNA-PKcS to phosphorylate p53 and histone H2AX is important for DNA repair activity, therefore we examined whether binding of Snail1 with DNA-PKcs affected this kinase activity of DNAPKcs. Snail1 overexpression in $\mathrm{NCl}-\mathrm{H} 460$ and DLD-1 cells inhibited DNA-PKcs kinase activity when a p53 peptide was used as a substrate (Figure $4 a$, left). Additionally, transfection of Si-Snail1 into $\mathrm{NCl}-\mathrm{H} 460$ cells showed a reversed effect. We treated cells with Si-DNA-PKcs as a positive control (Figure 4a, right). IR-induced DNA-PKcs kinase activity was also inhibited by Snail1 overexpression when a p53 peptide was used as a substrate (Figure 4b). Activation of DNA-PKcs downstream pathways (phospho-p53 and $\gamma-\mathrm{H} 2 \mathrm{AX}$ ) by IR which represents normal DNA-PKcs kinase activity, was attenuated by Snail1 overexpression, whereas 


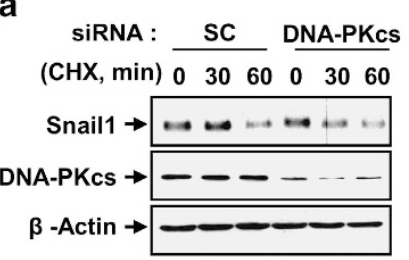

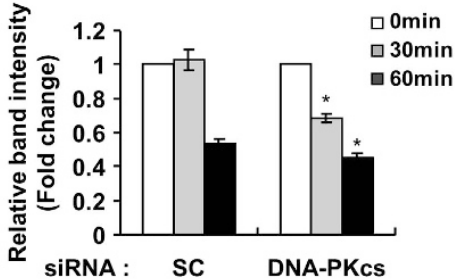

SiRNA : b

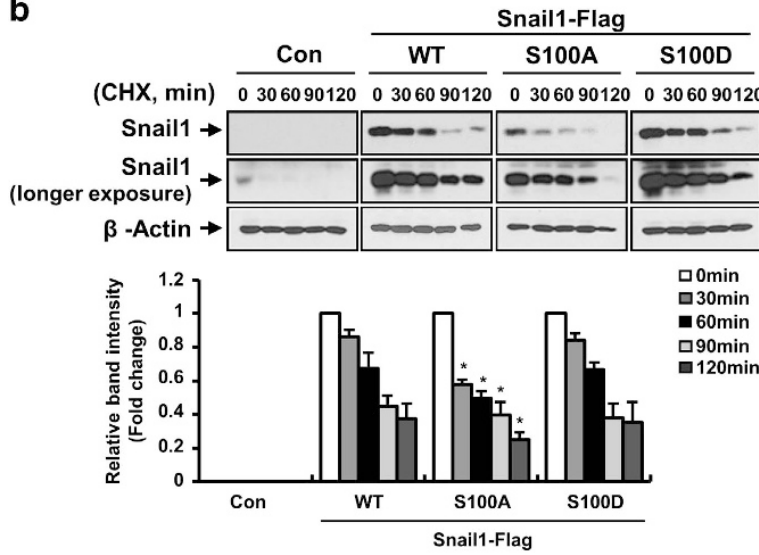

c
HA-Ub (+) Snail1-Flag

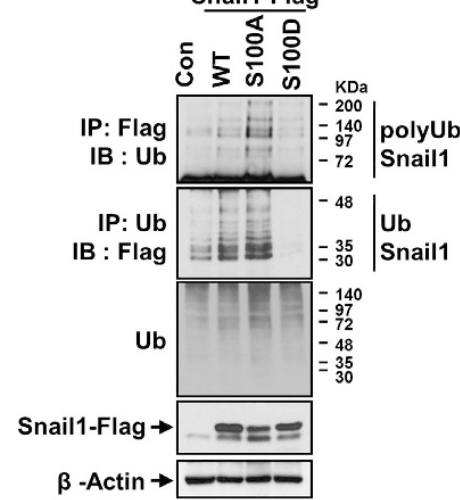

d Snail1

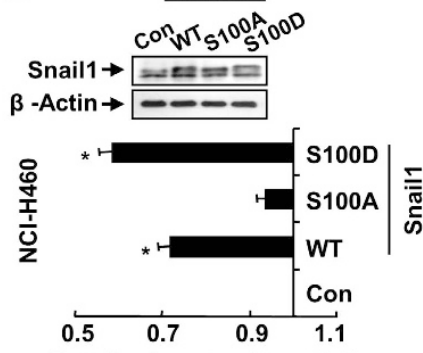

E-cadherin promoter activity
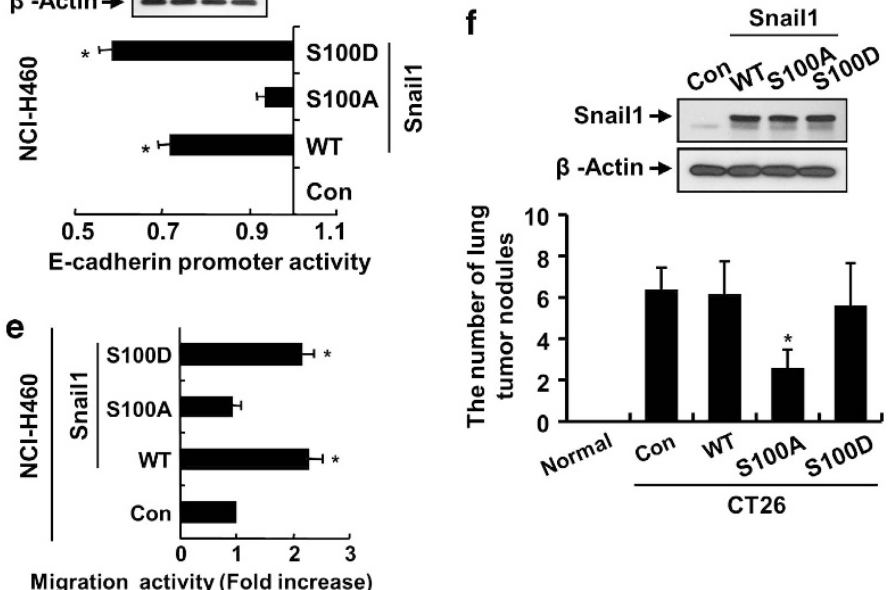

Figure 3 Snail1 phosphorylation at Ser100 by DNA-PKcs increased its protein stability. (a) Protein extracts were prepared at the indicated time points following CHX treatment $(20 \mu \mathrm{g} / \mathrm{ml}$ ) to Snail1-WT-overexpressing NCl-H460 cells with transfection of scrambled control (SC) or DNA-PKcs (Si-DNA-PKcs) Si-RNAs. Western blot analysis was then performed using an anti-Snail1 antibody (left). The relative protein band intensity was calculated from densitometric scans of the immunoblots with the control values set at 1 (right). ( $n=3$, data are presented as means \pm S.D., ${ }^{~}$ Significantly different from corresponding scrambled control Si-RNAs treated cells $(S C)$ at $\left.P<0.05\right)$. (b) Protein extracts were prepared at the indicated time points following CHX treatment $(20 \mu \mathrm{g} / \mathrm{ml})$ in Snail1-WT (WT), Snail1-Ser100A (S100A), and Snail1-Ser100D (S100D)overexpressing $\mathrm{NCl}-\mathrm{H} 460$ cells. Western blotting was performed using anti-Snail1 (upper) and the relative protein band intensity was then calculated by comparing densitometric scans of the sample immunoblots with the values of control samples set at 1 (lower). ( $n=3$, data are presented as means \pm S.D., * Significantly different from Snail1-WT cells at $P<0.05$ ). (c) For ubiquitination assays, DLD-1 cells were transfected with ubiquitin-HA and control, Snail1-WT, Snail1-S100A, and Snail1-S100D constructs. Cell lysates were immunoprecipitated and immunoblotted. (d) NCl-H460 cells were transiently transfected with Snail1-WT or mutant Snail1 (S100A or S100D) plasmids. A luciferase assay was then performed using the E-cadherin promoter. The promoter activity of control cells was set at 1 ( $n=3$, data are presented as means \pm S.D., *Significantly different from control untransfected cells at $P<0.05$; promoter activity: $1<$ activation, $1>$ inhibition). (e) NCl-H460 cells were transiently transfected with Snail1-WT or mutant types of Snail1 (S100A or S100D) plasmids. A migration assay was performed. The value of control cells was set at 1 ( $n=3$, data are presented as means \pm S.D. * Significantly different from control untransfected cells at $P<0.05$ ). (f) After stable transfection of Snail1-WT or mutant Snail1 S100A/S100D plasmids to CT26 colon carcinoma cells, western blot analysis was performed (upper). The metastasis of CT26 cells was assessed by the number of lung metastatic nodules and lung weight 14 days after intravenous injection of cells through the tail vein of the mice. Quantitative analysis of the number of lung metastatic nodules (lower). (Normal, no tumor cell injection; Con, CT26 cell injection; WT, Snail1-WT; S100A, Snail1-S100A; S100D, Snail-S100D). Data are presented as the means \pm S.D. of five mice from each group. *Significantly different from control cells injected mice at $P<0.05$ 
Si-Snail1 treatment of these cells showed reversed effects (Figure 4c and Supplementary Figure S5a). As DNA-PKcs phosphorylated Snail1 at Ser100, we determined whether this phosphorylation affected DNA-PKcs kinase activity. The Snail1-S100A protein did not inhibit IR-induced DNAPKcs kinase activity when a p53 peptide was used as a substrate, or its downstream effects, such as p53 phosphorylation at Ser15 and histone $\mathrm{H} 2 \mathrm{AX}$ phosphorylation at Ser139, although DNA-PKcs interacted with Snail1-S100A. However, Snail1-WT and Snail1-S100D inhibited IR-induced DNA-PKcs kinase activity when a 553 peptide was used as a substrate, and its downstream effects (Figures $4 d$ and e). The phosphorylation of Snail 1 at Ser104 by GSK-3 $\beta$ has been reported to affect Snail1 function, including E-cadherin promoter activity. ${ }^{15}$ We next determined whether phosphoSnail1 at Ser104 or 107 affected the normal kinase activity of DNA-PKcs. Inhibition of DNA-PKcs kinase activity by Snail1WT was not observed when the mutant Snail1-S100A was transfected into $\mathrm{NCl}-\mathrm{H} 460$ and $\mathrm{A} 549$ cells, and when the mutant Snail1-S104A/S107A was transfected, inhibition of DNA-PKcs kinase activity was still observed (Supplementary Figure S5b). Activation of DNA-PKcs downstream pathways by IR exposure was also attenuated by transfection with Snail1-WT or Snail1-S104A/S107 (Supplementary Figure S5c). These data suggested that DNA-PKcs phosphorylated Snail1 only at Ser100, and that this phosphorylation reciprocally inhibited DNA-PKcs kinase activity and its downstream pathways.

To examine whether the binding of Snail1 with DNA-PKcs is important in the inhibition of DNA-PKcs kinase activity by Snail1, WT or deletion mutants of Snail1 were transfected into $\mathrm{NCl}-\mathrm{H} 460$ cells. Snail1-WT transfection inhibited IR-induced DNA-PKcs kinase activity when p53 peptide was used as a substrate. However, a deletion mutant of amino acids 8-35 $(\Delta 8-35)$, which is a binding partner interacting with DNAPKcs, did not inhibit the kinase activity of DNA-PKcs, indicating that binding of Snail1 and DNA-PKcs is essential for the inhibition of DNA-PKcs kinase activity. Moreover, a deletion mutant of amino acids 81-109 ( $\Delta 81-109)$ did not inhibit the kinase activity of DNA-PKcs, either because of the absence of DNA-PKcs's phosphorylation site, Ser100 (Figure 4f).

Recruitment of DNA-PKcs to DNA DSBs was inhibited by Snail1. As DNA-PKcs is recruited to DNA DSB sites after DNA damage, ${ }^{16}$ we next determined whether the interaction of DNA-PKcs with Snail1 occurred at DSB sites. A DSB pulldown assay using exogenously transfected double stranded (ds) oligonucleotides demonstrated that Snail1 overexpressing $\mathrm{NCl}-\mathrm{H} 460$ or DLD1 cells inhibited the recruitment of DNA-PKcs or Ku80 to DNA damage sites, which is similar to Si-DNA-PKcs-treated cells (Figures $5 a$ and b). Addition of Snail1-His protein to Si-Snail1-treated $\mathrm{NCl}-\mathrm{H} 460$ cells inhibited the recovery or recruitment of DNA-PKcs or Ku80 to exogenously added ds oligonucleotides (Figure $5 \mathrm{c}$ ). To examine its physiologic relevance, we examined DSB repair activity. As was previously suggested, Snail1 overexpression to $\mathrm{NCl}-\mathrm{H} 460$ or DLD1 cells potentiates IR-induced comet-tail formation. At $24 \mathrm{~h}$ after exposure to a dose of $10 \mathrm{~Gy} I \mathrm{R}$, control cells showed recovery from DSB damage when examined by a comet assay; however, cells overexpressing Snail1 showed sustained DSB damage (Figure 5d). Similar phenomena were observed when NHEJ activity was detected by a plasmid-based DNA end joining assay in DLD1 cells, and when DNA-PKcs was absent these phenomena were not shown (Figure 5e).

Snail1 did not induce genomic instability and resistance to IR in DNA-PKcs-depleted cells. As impaired DNA repair activity and increased survival may affect genomic instability, ${ }^{17,18}$ we next examined aneuploidy in the cell population. An increased number of G2/M phase cells after IR was seen in DLD-1 cells overexpressing Snail1, a phenomenon similar to DNA-PKcs knockout cells (Figure 6a, upper). Moreover, when DNA-PKcs was knocked down by stable transfection of Sh-DNA-PKcs, Snail1 overexpression did not potentiate the increases of G2/M phase cells (Figure 6a, lower). A higher number of multinucleated cells ( $>4 N$ cells) was observed in Snail1-overexpressing cells after IR exposure, similar to Si-DNA-PKcs-transfected cells (Figure 6b). When these effects were examined using DNAPKcs-deficient cells (M059J), Snail1 overexpression did not induce G2/M phase arrest (Supplementary Figure S6a). Cell death data also suggested that Snail1 overexpression to DLD1 cells increased survival after 5 Gy IR, whereas Sh-DNAPKcs transfection restored this effect (Figure 6c), suggesting that Snail1-mediated radioresistance was observed only in the DNA-PKcs-expressing cells. When we examined cell survival using other cell line systems, such as $\mathrm{NCl}-\mathrm{H} 460$, Snail overexpression increased cell survival after IR, whereas SiSnail1 did not (Supplementary Figure S6b, left). Moreover, when these effects were examined using DNA-PKcs knockout cells (M059J), Snail1 overexpression did not increase survival (Supplementary Figure S6b, right). In vivo nude mice grafting data indicated that tumor growth with Snail1-overexpressed cells resisted IR compared to the control DLD-1 cell-grafted tumors. However, when additional Sh-DNA-PKcs was transfected to Snail1-overexpressed cells and these cells were grafted to the mice, the resistance against IR was inhibited (Figure 6d, Supplementary Figure S6c). From these data, it is thought that DNA-PKcs is essential for Snail1-mediated resistance when exposed to IR. Moreover, when chromosomal aberrations were measured in the first cycle of metaphase using DLD-1 cells (which have relatively low prevalence of chromosomal aberration) harvested $48 \mathrm{~h}$ and 100 mitoses into each treatment and analyzed by the $\mathrm{mFISH}$-technique, most aberrations were simple or complex types of translocations, breaks as well as loss or gain of chromosomes. Snail1 overexpression without IR dramatically increased the total chromosomal aberration number, and IR exposure to the cells overexpressing Snail1 resulted in the greatest induction of total chromosome aberrations and translocations (Table 1). From these data, Snail1-mediated genomic instability and resistance to DNA-damaging agents such as IR, is a DNAPKcs-dependent process.

\section{Discussion}

Although the role of DNA-PKcs in DNA repair is wellestablished and has been extensively studied, the mechanism 
by which DNA-PKcs is regulated in cellular systems, except for the response to DNA damage, remains unknown. In this study, we identified a novel function of DNA-PKcs as a regulator of Snail1. The direct interaction between DNA-PKcs and Snail1 induced Snail1 phosphorylation at Ser100, stabilizing the Snail1 protein and potentiating Snail1 functions such as E-cadherin promoter repression and metastasis properties. Snail1 phosphorylation reciprocally inhibited DNAPKcs kinase activity, impairing DNA-damage repair and induction of genomic instability. a
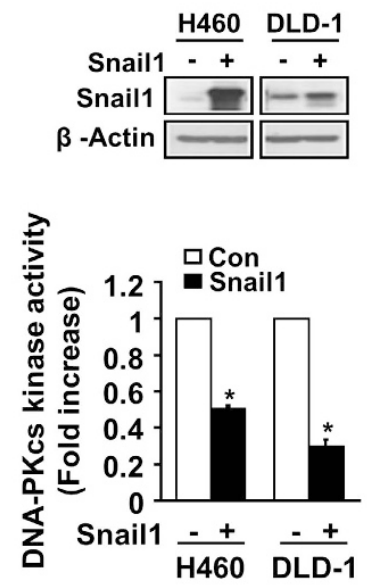

C

\section{DLD-1}

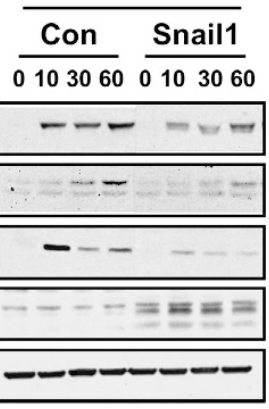

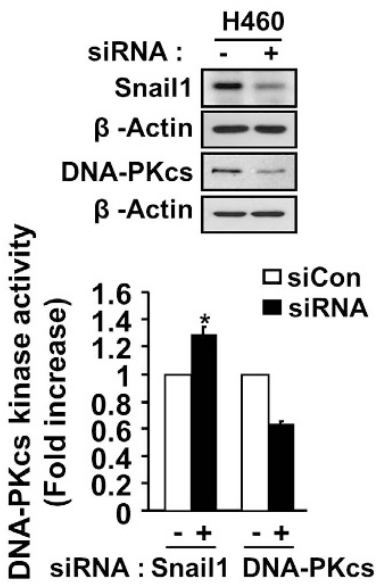
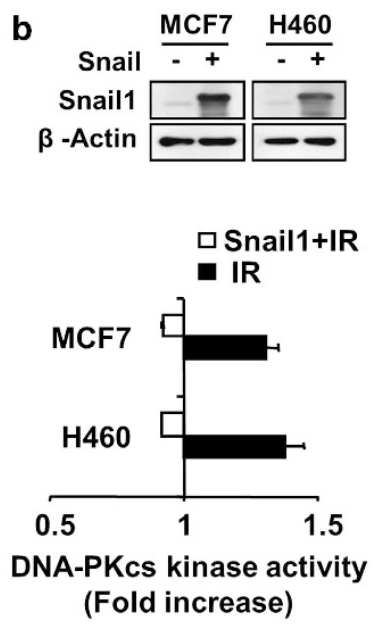

$\square$ Snail1+IR

- IR

d

(Fold increase)

d

DLD-1

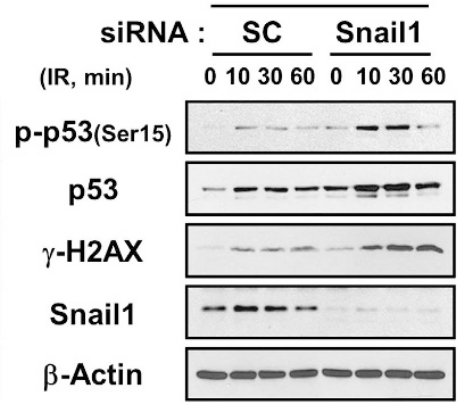

IP: DNA-PKcs

IB: Flag $\rightarrow--2=E$
Snail1 $\rightarrow-\infty$

DNA-PKcs $\rightarrow-\cdots$

$\beta$-Actin $\rightarrow-\infty-\infty$

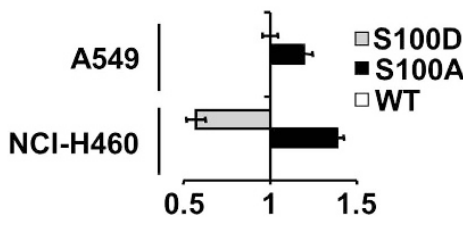

DNA-PKcs kinase activity (Fold increase) e

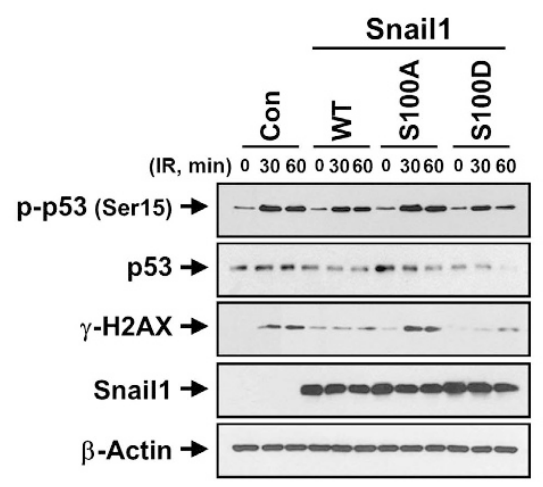

f

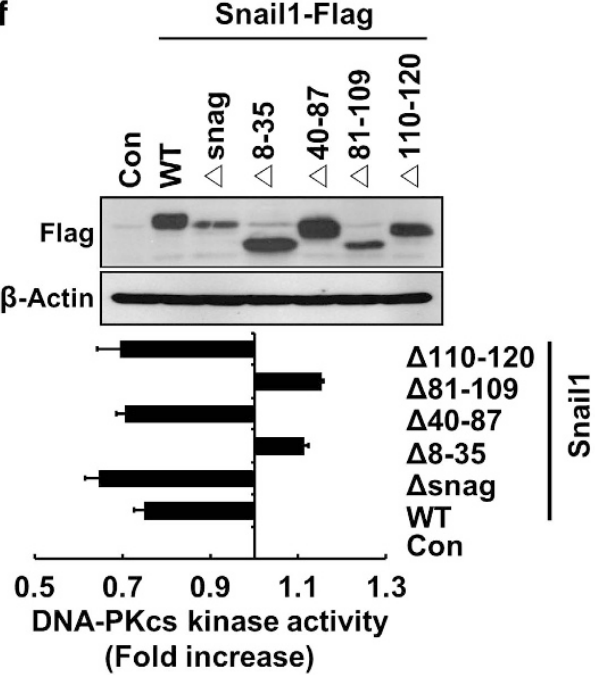


The serine/threonine kinase activity of DNA-PKcs is clearly a requirement for its role in NHEJ in the DNA repair process following IR, and many studies have functionally defined the relevant targets of DNA-PKcs. DNA-PKcs and related PI3K family members preferentially phosphorylate serines and threonines, followed by glutamine (S-T/Q sites). Considering the probability of DSB damage and the functional role of DNAPKcs in the DNA-repair system, the high levels of expression of DNA-PKcs in mammalian cells, especially primates, is a longstanding question regarding DNA-PKcs, ${ }^{19}$ and it suggests that substrates of DNA-PKcs other than DSB repair may exist.

The upstream stimulatory factor (USF), an E-box-binding transcription factor of fatty acid synthase, is a target of DNAPKcs in the regulation of metabolic gene activation. ${ }^{20}$ Our study also demonstrated that another E-box-binding transcription factor, Snail1, is phosphorylated by DNA-PKcs, followed by gain of function. Interestingly, the DNA-PKcs complex of USF and Snail1 contains the Ku protein. Possibly the substrates and functional roles of DNA-PKcs in cellular regulation are more permissive than DSB repair. Indeed, our results showed the co-expression of Snail1 and DNA-PKcs in several human colon and lung tissues.

In this study, we demonstrated that DNA-PKcs phosphorylates Snail1 at Ser100, which has the DNA-PKcs phosphorylation site $\mathrm{SQ}$. The $\mathrm{N}$-terminal Snail1-binding domain with DNA-PKcs (amino acids 8-35) differs from the phosphorylation site for DNA-PKcs (Ser100), and the phosphorylation status of Snail1 did not affect the binding activity with DNAPKcs. This suggests that the molecular interaction between Snail1 and DNA-PKcs, and substrate phosphorylation are independent. Although primed phosphorylation by other kinases and the exact GSK-3 $\beta$ phosphorylation site(s) on Snail1 have not been completely identified, the phosphorylation of both Ser104 and Ser107 are essential in N-terminaldirected serial phosphorylation by GSK-3 $\beta .^{20}$ Thus, it is reasonable that phosphorylation of Snail1 at Ser100 may block GSK-3 $\beta$-mediated phosphorylation and the subsequent degradation process. Our study also demonstrated that the phospho-mimic mutant of Snail1 (Ser100D) and DNA-PKcs activation resulted in an increased Snail1 half-life and repressor function of the E-cadherin promoter. DNA-PKcsspecific phosphorylation of Snail1 at Ser100 was not induced by GSK-3 $\beta$, and GSK-3 $\beta$ activation is not a common phenomena during the DNA-damage response to IR exposure (Supplementary Figure S6d). Therefore, we propose that during a DNA-damage response triggered by IR, DNA-PKcs phosphorylation of Snail1 at Ser100 is preferentially induced and this phosphorylation may block GSK-3 $\beta$-mediated additional phosphorylation at Ser104 and Ser107.
It was suggested that the phospho-defective mutant of two serine residues of Snail1 at Ser96 and Ser100, DS(96)GxxS(100), $\beta$-TrCP destruction motif showed an increased half-life after $\mathrm{CHX}$ treatment. ${ }^{12}$ However, one of our serine residue mutants, Snail1-S100A, showed the opposite effects: a decreased half-life of Snail1, while the phospho-mimetic mutant, Snail1-S100D, showed an increased protein half-life. We do not know exactly how this discrepancy occurs. One possibility may be the different regulation of protein stability by simultaneous or additional phosphorylation of Snail1 at Ser96 altering the increased protein stability of Snail1 by phosphorylation at Ser100.

DNA-PKcs activity is closely related to the DNA-damage sensitivity and DNA-PKcs deficiency increased the damage sensitivity. ${ }^{21,22}$ However, our data suggested that DNA-PKcs activity and downstream pathways triggered by IR were inhibited by Snail1, which resulted in damage resistance and genomic instability. This discrepancy might be interpreted to mean that decreased kinase activity of DNA-PKcs alone was not responsible for the damage survival and genomic instability. Instead, phosphorylation of Snail1 at Ser100 by DNA-PKcs might be more essential factor for the damage resistance and genomic instability. Our data also indicated that knockdown of DNA-PKcs alone induced radiation sensitivity when Snail1 expression was low (data not shown). Therefore, if both Snail1 and DNA-PKcs are co-expressed in cancer cells, DNA-damage agents such as IR, activates DNA-PKcs and increases the Snail function by its phosphorylation at Ser100, which may be more related to damage resistance and genomic instability. Indeed, there is research reporting that decrease of single DNA-PKcs activity was not a major factor for damage sensitivity. ${ }^{23,24}$ Another interpretation is that DNA-PKcs-mediated phosphorylation of $p 53$, a substrate of DNA-PKcs, ${ }^{21,25-28}$ was decreased by Snail1 overexpression. Therefore, decreased p53 function by Snail 1 may be also involved in the damage resistance, ${ }^{29,30}$ which resulted in damage survival and genomic instability.

In summary, our findings demonstrated that the interaction of Snail1 with DNA-PKcs led to the phosphorylation of Snail1 at Ser100. Phosphorylated Snail1 increased the protein stability of Snail1 with functional potentiation. Moreover, phosphorylated Snail1 showed feedback inhibition of DNAPKcs kinase activity resulting in inhibited recruitment of DNAPKcs to DSB sites, impaired DNA repair activity, and ultimately, induction of genomic instability. Thus, a novel function of DNA-PKcs in the regulation of Snail1 suggests that it acts as an oncogenic molecule, phosphorylating Snail1, which is involved in the inhibition of normal DSB repair, leading to an increase in genomic instability and aggressive tumor characteristics (Figure 6e).

Figure 4 The kinase activity of DNA-PKcs was inhibited by phospho-Snail1 at Ser100. (a) Nuclear extracts of Snail1 overexpressing NCI-H460 and DLD-1 cells were assayed for DNA-PKcs kinase activity (left). Scrambled control (SC), Snail1 (Si-Snail1), or DNA-PKcs (Si-DNA-PKcs) Si-RNAs were transfected into NCl-H460 cells (right). (b) MCF7 cells and NCl-H460 cells stably expressing an empty vector or Snail1 were exposed to $5 \mathrm{~Gy}(\mathrm{IR})$ and nuclear extracts were assayed for DNA-PKcs kinase activity. The SAM membrane or a $3 \mathrm{~mm}$ filter disc was analyzed using a phosphoimager system and values of the control were set to 1 ( $n=3$, data are presented as means \pm S.D. *Significantly different from the data of the corresponding control cells at $P<0.05$. (c) DLD-1 cells were transiently transfected with Con and Snail1-WT (left), or SC and SiSnail1 (right). Cells were then exposed to a dose of $5 \mathrm{~Gy} \mathrm{IR}$ and IB was performed at the indicated time points. (d) NCl-H460 cells were transiently transfected with Con, Snail1WT, Snail1-S100A, or Snail1-S100D plasmid. Western blotting or IB was conducted following IP (upper). DNA-PKcs activity was also performed. The SAM membrane or a $3 \mathrm{~mm}$ filter disc was analyzed using a phosphoimager system and values of the control were set to 1 (lower). (e) Western blots were also performed at the indicated time points following treatment with 5 Gy IR. The result represents one of three independent experiments (a-c, and e). (f) Snail1-WT or mutant type Snail1 (deletion of amino acid sequences 8-35) was transfected into NCl-H460 cells (upper). Nuclear extracts were assayed for DNA-PKcs kinase activity. The SAM membrane or 3 mm filter disc was analyzed using a phosphoimager system and control values were set to 1 (lower) 
a

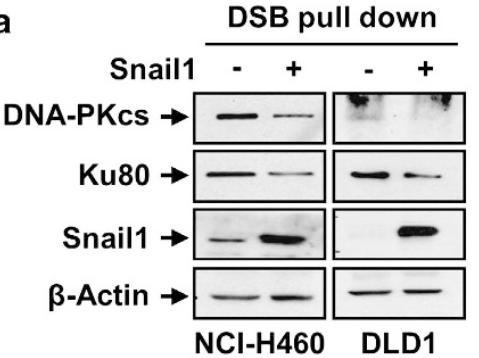

C

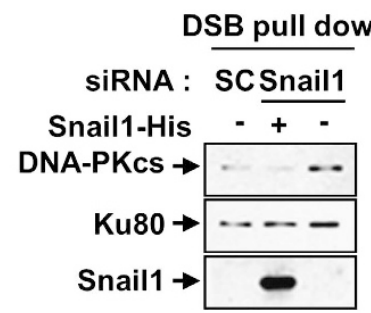

d

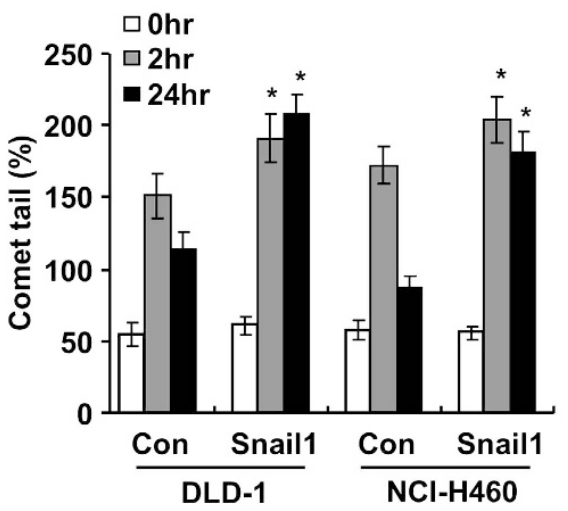

b

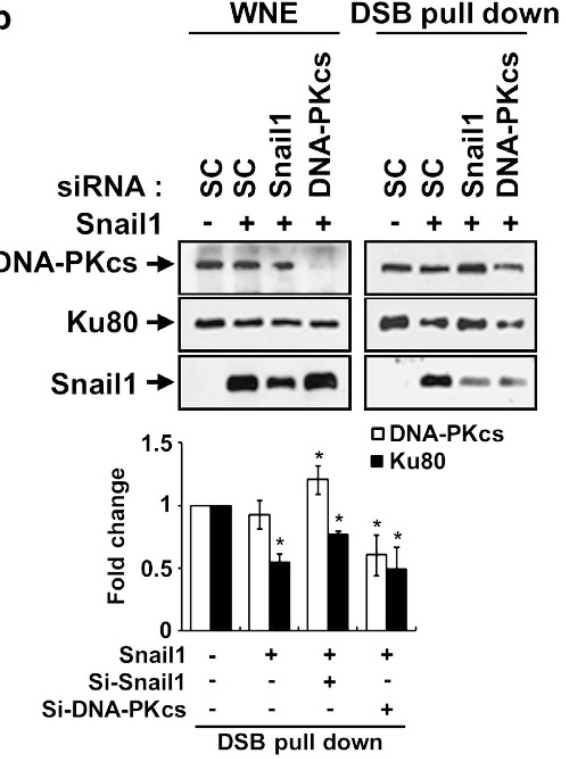

e

SIRNA : SC DNA-PKcs

Snail1 $\overline{-+} \overline{-+}$
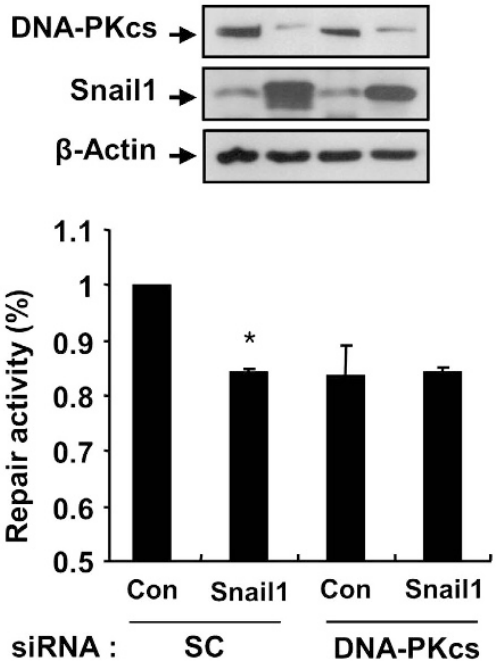

Figure 5 Recruitment of DNA-PKcs to DNA DSBs was inhibited by Snail1. (a) The protein levels of DNA-PKcs, Ku80, and Snail1 from dsDNA pull-down lysates in nuclear extracts of NCI-H460 and DLD1 cells overexpressing Snail1 were analyzed by western blotting. (b) Scrambled control (SC), DNA-PKcs (Si-DNA-PKcs), or Snail1 (Si-Snail1) Si-RNAs were transfected into control and Snail1-overexpressing NCl-H460 cells. The protein levels of DNA-PKcs, Ku80, and Snail1 in the dsDNA pull-down lysates, as well as in complete whole-nuclear extracts (WNE) were analyzed (upper). The relative protein band intensity was calculated by comparing densitometric scans of the sample immunoblots with the values of control samples set at 1 (lower). ( $n=3$, data are presented as means \pm S.D., * Significantly different from corresponding control cells at $P<0.05$ ). (c) SC and Si-Snail1 were transfected into NCI-H460 cells. Immobilized DNA was mixed with nuclear extract in the presence or absence of purified Snail1-His recombinant proteins $(50 \mathrm{ng} / \mathrm{ml}$ ). (d) DLD-1 and NCl-H460 cells overexpressing Snail1-WT or a vector control were exposed to a dose of 5 Gy IR. Cells were harvested at the indicated time points. DSBs were determined by use of the comet assay. Values represent the mean \pm S.D. of data from up to three independent experiments ( ${ }^{*}$ Significantly different for the data of corresponding control cells at $P<0.05$ ). (e) After transfection of Snail1-WT to DLD-1 cells, or after transfection of Snail1-WT to Si-DNA-PKcstransfected DLD-1 cells, a DNA end-joining assay was performed by use of the pGL2 vector. Error bars indicate means \pm S.D. of three repeated determinations ${ }^{\star} P<0.05$ versus corresponding control cells)

\section{Materials and Methods}

Plasmids. DNA-PKcs deletion constructs were generated by isolating internal regions using PCR from the full-length CDNA for DNA-PKcs, which was a kind gift of Dr. Katheryn Meek (Michigan State University, East Lansing, MI, USA). The PCR fragments were inserted into the $\mathrm{PCMV}^{9}$ expression vector using Notl and $\mathrm{Kpnl}$ restriction sites, and the products were verified by sequencing. Seven deletion constructs of DNA-PKcs with C-terminal Myc epitope tails were prepared
(Cosmogenetech Co., Ltd., Seoul, Korea). Expression vectors pCR3.1-Snail1Flag and Snail1 mutant proteins with Flag epitope tails, including the S100A, S100D, S104A, and S107A mutants were prepared as described previously. ${ }^{13,20}$

Cell culture. MCF7 human breast cancer cells, M059J/M069K human glioblastoma cells, DLD-1 human colorectal adenocarcinoma cells, and CT26 murin colon carcinoma cells were cultured in Dulbecco's minimal essential medium 
a

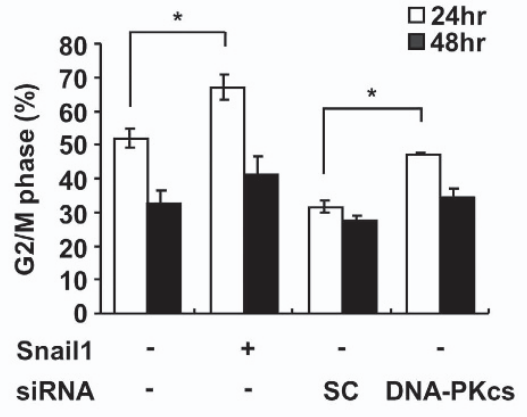

d
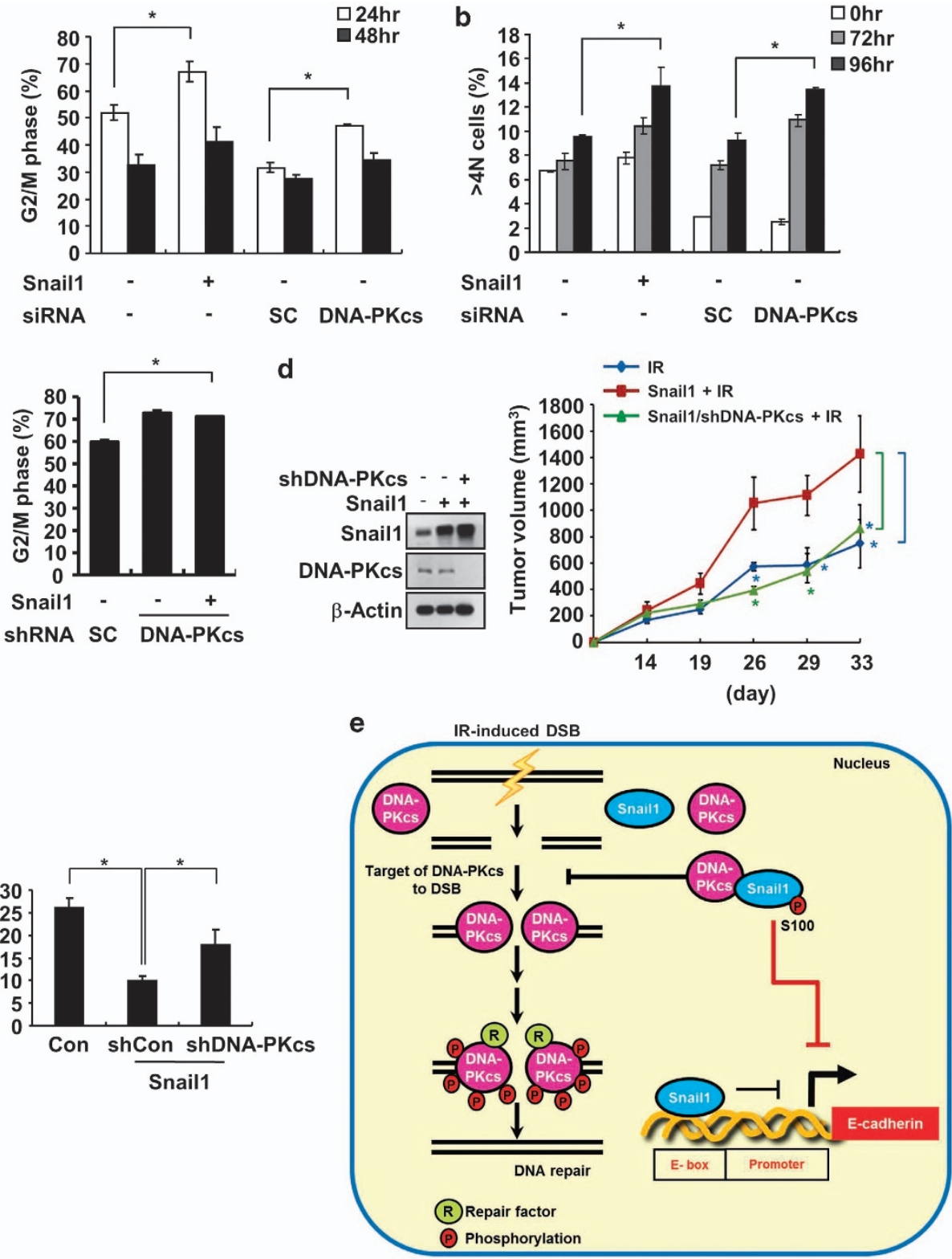

Figure 6 Snail1 did not induce genomic instability in DNA-PKcs-depleted cells. (a) DLD-1 cells (Con) or DNA-PKcs Si-RNAs (Si-DNA-PKcs) were transfected into DLD-1 cells (upper), and Con or Snail1-WT was transfected to DLD-1 cells with a stable transfection of shDNA-PKcs (lower). At 24 and $48 \mathrm{~h}$ after IR (5 Gy), flow cytometric analysis after PI staining was determined. (b) Snail1-WT and DNA-PKcs (Si-DNA-PKcs) Si-RNAs were transfected into DLD-1 cells. Multinucleated giant cells were counted at 72 and $96 \mathrm{~h}$ after exposure to $5 \mathrm{~Gy}$ of IR. (c) After $48 \mathrm{~h}$ of $5 \mathrm{~Gy}$ of IR, cell death was analyzed by FACS. Error bars indicate the means \pm S.D. of three repeated determinations (a-c, $\left.{ }^{*} P<0.05\right)$. (d) After transfection of Sh-DNA-PKcs to DLD-1 cells, stably transfected Snail 1 cells were produced (left). DLD-1 cells, Snail1, or Snail1/shRDNA-PKcs stable cells were injected subcutaneously into BALB/c nude mice ( $n=4 /$ group). Radiation ( $8 \mathrm{~Gy}$ ) with local regional application was applied when the tumor reached a minimal volume of $200 \mathrm{~mm}^{3}$. Tumor size was measured twice weekly. Results are the means \pm S.D. of four mice of each group $\left({ }^{*} P<0.05\right)$ (right). (e) Reciprocal regulation between DNA-PKcs and Snail1 in defective DNA repair activity and increased Snail1 stability. A direct interaction between DNA-PKcs and Snail1 induces phosphorylation of Snail1 at Ser100, resulting in increased functional Snail activity. DNA-PKcs-mediated phosphorylation of Snail1 at Ser100 blocks the DSB repair process by inhibiting the catalytic activity of DNA-PKcs. The mutual relationship between DNA-PKcs and Snail1 is critical for defective DNA repair activity, which affects genomic instability and the migration of tumor cells

(DMEM; GIBCO, Gaithersburg, MD, USA), supplemented with heat-inactivated $10 \%$ fetal bovine serum (FBS; GIBCO) and antibiotics. NCI-H460 human non-small cell carcinoma and A549 human lung carcinoma cells were cultured in RPMI (GIBCO), supplemented with heat-inactivated 10\% FBS (GIBCO) and antibiotics.

Antibodies and reagents. $\mathrm{CHX}$, propidium iodide (PI), Hoechst 33258 , and a monoclonal antibody for Flag were purchased from Sigma (St. Louis, MO, USA).
Monoclonal antibodies for DNA-PKcs, Ku80, Cyclin B1, p53, GSK3- $\beta$, and predesigned siRNAs for human DNA-PKcs, Ku80, Snail1, and a negative control SiRNA were purchased from Santa Cruz Biotechnology (Santa Cruz, CA, USA). Anti-Snail1 and p-p53 were purchased from Cell Signaling Technology (Danvers, MA, USA). Anti-p-DNA-PKcs (Ser2056) was purchased from Abcam (Cambridge, MA, USA), and $\gamma-\mathrm{H} 2 \mathrm{AX}$, Anti-p-MPM-2, and Anti-p-Histone H3 were purchased from Upstate (Charlottesville, VA, USA). Anti-p-Snail1 (Ser 100) was raised in a rabbit against a synthetic peptide corresponding to residues of human Snail1 
Table 1 Number of the different chromosome aberration types in Snail1-overexpressed cells and controls

\begin{tabular}{|c|c|c|c|c|c|c|c|c|}
\hline \multicolumn{9}{|c|}{ Different type of chromosome aberration } \\
\hline $\begin{array}{l}\text { Treatment } \\
\text { groups }\end{array}$ & Translocation & $\begin{array}{c}\text { Chromosome } \\
\text { breaks }\end{array}$ & $\begin{array}{c}\text { Loss of } \\
\text { chromosome }\end{array}$ & $\begin{array}{c}\text { Gain of } \\
\text { chromosome }\end{array}$ & Ring & $\begin{array}{c}\text { Total } \\
\text { chromosomal } \\
\text { aberration }\end{array}$ & $\begin{array}{l}\text { Induction } \\
\text { cells with } \\
\text { aberration }\end{array}$ & $\begin{array}{c}\text { Cells with } \\
\text { chromosomal } \\
\text { aberrations (\%) }\end{array}$ \\
\hline \multicolumn{9}{|c|}{ Normal $(46, X Y)$} \\
\hline Control & $1^{a}$ & 2 & 7 & 17 & 0 & 27 & & 23.81 \\
\hline 5 Gy & 21 & $1 \overline{2}$ & 13 & 31 & 0 & 77 & & 89.74 \\
\hline \multicolumn{9}{|c|}{ Snail $(46, X Y)$} \\
\hline Control & $11^{\mathrm{b}}$ & 16 & 70 & 38 & 0 & 134 & 496.30 & 52.59 \\
\hline 5 Gy & 133 & 37 & 49 & 18 & 1 & 238 & 368.83 & 97.37 \\
\hline
\end{tabular}

One-hundred cells were analyzes per treatment.

${ }^{\mathrm{a} C o n t r o l: ~} \mathrm{t}(4: 11)$

${ }^{b}$ Snail1-induced translocation: $t(1: 2), t(4: 5), t(1: 17), t(1: 4), t(13: 19), t(11: 22), t(1: 12), t(3: 4), t(14: 16), t(11: 13), t(1: 4)$

(phosphorylated at Ser100) and further purified by affinity chromatography (Young In Frontier, Seoul, Korea). The human recombinant glutathione S-transferase (GST) fusion proteins DNA-PKcs (DNA-PKcs amino acids 4019-4128) was purchased from Abnova (Paseo Del Prado Walnut, CA, USA).

Western blot analysis. Cells were lysed in lysis buffer $(20 \mathrm{mmol} / \mathrm{Tris} / \mathrm{HCl}$, $\mathrm{pH}$ 8.0; $2 \mathrm{mmol} / \mathrm{l}$ ethylene diamine tetraacetic acid; $137 \mathrm{mmol} / / \mathrm{NaCl} ; 1 \mathrm{mmol} / /$ NaVO4; $1 \mathrm{mmol} / \mathrm{l}$ phenylmethylsulfonyl fluoride; $10 \%$ glycerol; and $1 \%$ Triton $\mathrm{X}-100$, and a protease inhibitor). Lysates were clarified by centrifugation at $15000 \mathrm{~g}$ for $10 \mathrm{~min}$. Protein samples were then size-fractionated by electrophoresis, and proteins were electrotransferred to nitrocellulose membrane. The membranes were immunoblotted with primary antibodies and treated with horseradish peroxidase-conjugated anti-lgG. Immunoblotted proteins were visualized using a chemiluminescence ECL system (Amersham Pharmacia Biotech, Little Chalfont, UK).

In vitro translation and SDS-polyacrylamide gel electrophoresis analysis. Coupled in vitro transcription/translation of the full-length WT Snail1-Flag proteins was performed using the TNT T7 Quick-Coupled Transcription/ Translation System (Promega, Madison, WI, USA). T7 RNA polymerase-driven in vitro transcription reactions were followed by in vitro translations in the presence of L- $\left[{ }^{35} \mathrm{~S}\right]$ methionine using rabbit reticulocyte lysates. In vitro translation products were electrophoresed through 10\% SDS-PAGE and exposed to Kodak X-Omat film.

DNA-PKcs kinase assay. DNA-PKcs kinase activity was analyzed using the signaTECT DNA-PKcs assay system (Promega). Nuclear extracts were isolated for DNA-PKcs kinase activity analysis. The phosphorylation reactions were carried out in the presence of $\gamma \mathrm{ATP}^{32}{ }^{32} \mathrm{P}$ (NEN Life Science, Boston, MA, USA) for $5 \mathrm{~min}$ at $30^{\circ} \mathrm{C}$ with $25 \mu \mathrm{g}$ of biotinylated-p53 peptide, -A peptide, and $-B$ peptide (p53; biotin-EPPLSQEAFADLWKK; Promega, PeptA; biotinSGKGS(100)QPP, and PeptB; biotin-PS(104)PPS(107)PA) as the substrate. The efficiency of ${ }^{32} \mathrm{P}$ labeling of the substrate was measured using a phosphorimager.

In vitro ubiquitination assay. For cell-based ubiquitination assays, DLD-1 cells were transfected with HA-ubiquitin and Snail1-Flag (Snail1-WT, Snail1S100A, or Snail1-S100D) constructs. After transfection, cells were lysed with immune precipitation assay buffer, and samples were briefly sonicated. After centrifugation, clear lysates were immunoprecipitated with anti-Flag (Sigma) or anti-Ub (Santa Cruz) antibodies. Immunocomplexes were analyzed by western blot using anti-Ub or anti-Flag antibodies.

DNA end-joining assay. The control pGL2 plasmid (Promega) was linearized using Hindlll, which cuts between the promoter and the luciferase cDNA, or left untreated. Cells were transfected with the linearized or uncut plasmid $(0.5 \mu \mathrm{g})$ and $200 \mathrm{ng}$ of $\beta$-galactosidase expression vector. The cells were harvested $48 \mathrm{~h}$ later and the luciferase activity was then assayed, with the results being normalized to the $\beta$-galactosidase expression (Promega). All results represent the mean of three independent experiments.
In vitro migration assay. Cell migration was assayed using a Boyden chamber assay, as described previously. ${ }^{31}$ Cells were harvested with trypsin $(0.1 \mathrm{mg} / \mathrm{ml})$, centrifuged, counted, and resuspended in serum-free media. Cells were plated on the upper side of a collagen-treated, polycarbonate membrane separating the two chambers of $6.5-\mathrm{mm}$ Transwell culture plates (Costar, Corning, NY, USA). After $16 \mathrm{~h}$, cells on the upper face of the membrane were scraped using a cotton swab and cells that migrated to the lower face of the membrane were stained with DiffQuick Wright-Giemsa solution (Baxter, Deerfield, IL, USA).

Linear dsDNA-associated protein pull-down assay. Nuclear extracts were isolated for a dsDNA pull-down assay. A biotinylated oligonucleotide $(1 \mathrm{~kb})$, which was generated by PCR amplification of pcDNA3 $(5.4 \mathrm{~kb})$ with the biotinylated forward primer $5^{\prime}$-GACTCTCAGTACAATCTGCTCTGA-3' and reverse primer $5^{\prime}$-AGCTCTAGCATTTAGGTGACACT-3' was immobilized on streptavidin beads (Sigma). Immobilized DNA was mixed with nuclear extracts and incubated for $3 \mathrm{~h}$ at $4^{\circ} \mathrm{C}$. The beads were washed with buffer $\mathrm{D}(10 \mathrm{mM}$ Tris, $\mathrm{pH} 7.6$, and $100 \mathrm{mM} \mathrm{NaCl}$ ) and boiled for $5 \mathrm{~min}$ in $2 \times$ SDS sample buffer. Double-stranded DNA-associated proteins were analyzed by SDS-PAGE using enhanced chemiluminescence detection (ECL, Amersham).

Cell cycle analysis. For cell cycle analysis, cells were fixed in $80 \%$ ethanol at $4{ }^{\circ} \mathrm{C}$ for at least $18 \mathrm{~h}$. The fixed cells were then washed once with PBS-EDTA and resuspended in $1 \mathrm{ml}$ of PBS. After the addition of $10 \mu \mathrm{l}$ each of PI $(5 \mathrm{mg} / \mathrm{ml})$ and RNase $(10 \mathrm{mg} / \mathrm{ml})$, the samples were incubated for $30 \mathrm{~min}$ at $37^{\circ} \mathrm{C}$ and analyzed using a FACScan flow cytometer (Becton Dickinson, Franklin Lakes, NJ, USA).

Detection of cell aneuploidy. Cells were plated on glass slides and irradiated. After 72 or $96 \mathrm{~h}$, cells were fixed in $70 \%$ ethanol, washed with PBS, and incubated with $1 \mu \mathrm{g} / \mathrm{ml}$ bisbenzimide trihydrochloride in PBS (Hoechst 33258) for $30 \mathrm{~min}$ in the dark. Specimens were viewed by fluorescence microscopy using an Olympus BX-40 microscope. Nuclear morphology was examined for signs of aneuploidy, such as the presence of micronuclei and macronuclei.

Analysis of DNA damage by use of the comet assay. Cells were exposed to IR (10 Gy) and subjected to a comet assay to detect DNA damage and repair at the level of single cells, using a commercially available assay system (Trevigen, Gaithersburg, MD, USA). After treatment with IR, cells were harvested and mixed with low-melting temperature agarose. After lysis, electrophoresis was performed at $1 \mathrm{~V} / \mathrm{cm}$ and $15 \mathrm{~mA}$ for $40 \mathrm{~min}$. Slides were stained with SYBG green dye for $10 \mathrm{~min}$. Twenty randomly selected cells per sample were captured under a Zeiss fluorescent microscope and digital fluorescent images were obtained using Komet software (Andor, Belfast, UK). The comet distant moment was proportional to the amount of DNA damage present in the individual nuclei and was measured by the Olive tail moment using the Komet software.

Tumor metastases. All protocols involving mice were approved by the Institutional Animal Care and Use Committee of the Korea Institute of Radiological 
and Medical Sciences. To generate lung metastases, $2 \times 10^{6}$ CT26 cells were injected into the tail vein. Lungs were harvested 2 weeks after cell injection, weighed, and fixed in formalin.

Immunohistochemistry. Tissue microarrays of colon and lung cancer tissues were used for the immunostainning of Sanil1 and DNA-PKcs. The cancer tissue array used was ones of AccuMax array (Petagen Inc, Seoul, Korea). Array slides were deparaffinized and rehydrated using xylene and alcohol, and for immunoperoxidase labeling, endogenous peroxidase was blocked with $0.3 \% \mathrm{H}_{2} \mathrm{O}_{2}$ in absolute methanol for $15 \mathrm{~min}$ at room temperature. Primary DNA-PKcs or Snail1 antibody was reacted with the tissue for $2 \mathrm{~h}$ in a humid chamber at room temperature and washed with PBS for $10 \mathrm{~min}$, and the sections were incubated for $20 \mathrm{~min}$ at room temperature with secondary antibody. After additional incubation with streptavidin-HRP for 10 min, immunoreactive sites were visualized using $3,3^{\prime}$ diaminobenzidine for $5 \mathrm{~min}$. The sections were counterstained with Harris hematoxylin, dehydrated, and mounted with coverslips.

Statistical analyses. Student's $t$-test and an analysis of variance (ANOVA) were used to determine significant differences between the experimental groups. Statistical analyses were performed using GraphPad Prism 5.0 (Graph Pad software, San Diego, CA, USA). Null hypotheses of no difference were rejected if $P$-values were less than 0.05 .

\section{Conflict of Interest}

The authors declare no conflict of interest.

Acknowledgements. This work was supported by a grant of the Advanced Research Center for Nuclear Excellence (2011-0031696), and a grant of MidCareer Researcher Program (2011-0013364) of the National Research Foundation of Korea (NRF), funded by the Korean government (MEST). This work was also supported by an Ewha Global Top5 Grant 2011 from Ewha Womans University.

\section{Author contributions}

B-JP and HRS performed most of the experiments and data analysis, H-JL did animal experiment of tumor regression, YBJ did in vivo migration experiment, E-JK performed chromosome aberration analysis. NHK, HSK, and Nam HW made the Snail mutants' constructs and they first identified that DNA-PKcs is the protein that interacted with Snail1. JIY and Y-SL designed the experiments, analyzed the data, coordinated the study group, and wrote the manuscript.

1. Collis SJ, DeWeese TL, Jeggo PA, Parker AR. The life and death of DNA-PK. Oncogene 2005; 24: 949-961.

2. Lees-Miller SP, Meek K. Repair of DNA double strand breaks by non-homologous end joining. Biochimie 2003; 85: 1161-1173.

3. Weterings E, Van Gen DC. The mechanism of non-homologous end-joining: a synopsis of synapsis. DNA Repair (Amst) 2004; 3: 1425-1435.

4. Weterings $E$, Chen DJ. The endless tale of non-homologous end-joining. Cell Res 2008; 18: $114-124$.

5. Lévy N, Martz A, Bresson A, Spenlehauer C, de Murcia G, Ménissier-de Murcia J. XRCC1 is phosphorylated by DNA-dependent protein kinase in response to DNA damage. Nucleic Acids Res 2006; 34: 32-41.

6. Kajita M, McClinic KN, Wade PA. Aberrant expression of the transcription factors snail and slug alters the response to genotoxic stress. Mol Cell Biol 2004; 24: 7559-7566.

7. Mani SA, Guo W, Liao MJ, Eaton EN, Ayyanan A, Zhou AY et al. The epithelialmesenchymal transition generates cells with properties of stem cells. Cell 2008; 133: 704-715.

8. Kurrey NK, Jalgaonkar SP, Joglekar AV, Ghanate AD, Chaskar PD, Doiphode RY et al. Snail and slug mediate radioresistance and chemoresistance by antagonizing p53mediated apoptosis and acquiring a stem-like phenotype in ovarian cancer cells. Stem Cells 2009; 27: 2059-2068.

9. Anderson CW, Lees-Miller SP. The nuclear serine/threonine protein kinase DNA-PK. Crit Rev Eukaryot Gene Expr 1992; 2: 283-314.
10. Lees-Miller SP, Sakaguchi K, Ullrich SJ, Appella E, Anderson CW. Human DNA-activated protein kinase phosphorylates serines 15 and 37 in the amino-terminal transactivation domain of human p53. Mol Cell Biol 1992; 12: 5041-5549.

11. Lees-Miller SP. The DNA-dependent protein kinase, DNA-PK: 10 years and no ends in sight. Biochem Cell Biol 1996; 74: 503-512

12. Zhou BP, Deng J, Xia W, Xu J, Li YM, Gunduz M et al. Dual regulation of Snail by GSK3beta-mediated phosphorylation in control of epithelial-mesenchymal transition. Nat Cell Biol 2004; 6: 931-940.

13. Zhang MZ, Xu J, Yao B, Yin $H$, Cai $Q$, Shrubsole MJ et al. Inhibition of 11betahydroxysteroid dehydrogenase type II selectively blocks the tumor COX-2 pathway and suppresses colon carcinogenesis in mice and humans. J Clin Invest 2009; 119: 876-885.

14. Morimoto K, Satoh-Yamaguchi K, Hamaguchi A, Inoue Y, Takeuchi M, Okada M et al. Interaction of cancer cells with platelets mediated by Necl-5/poliovirus receptor enhances cancer cell metastasis to the lungs. Oncogene 2008; 27: 264-273.

15. Yook JI, Li XY, Ota I, Fearon ER, Weiss SJ. Wnt-dependent regulation of the E-cadherin repressor snail. J Biol Chem 2005; 280: 11740-11748.

16. Uematsu N, Weterings $\mathrm{E}$, Yano K, Morotomi-Yano K, Jakob B, Taucher-Scholz G et al. Autophosphorylation of DNA-PKcs regulates its dynamics at DNA double-strand breaks. J Cell Biol 2007; 177: 219-229.

17. Pastwa E, Blasiak J. Non-homologous DNA end joining. Acta Biochim Pol 2003; 50: 891-908.

18. Stucki M, Clapperton JA, Mohammad D, Yaffe MB, Smerdon SJ, Jackson SP. MDC1 directly binds phosphorylated histone $\mathrm{H} 2 \mathrm{AX}$ to regulate cellular responses to DNA doublestrand breaks. Cell 2005; 123: 1213-1226.

19. Meek K, Dang V, Lees-Miller SP. DNA-PK: the means to justify the ends? Adv Immunol 2008; 99: 33-58

20. Yook Jl, Li XY, Ota I, Hu C, Kim HS, Kim NH et al. A Wnt-Axin2-GSK3beta cascade regulates Snail1 activity in breast cancer cells. Nat Cell Biol 2006; 8: 1398-1406.

21. Wong RH, Chang I, Hudak CS, Hyun S, Kwan HY, Sul HS. A role of DNA-PK for the metabolic gene regulation in response to insulin. Cell 2009; 136: 1056-1072.

22. Zhao BX, Chen HZ, Du XD, Luo J, He JP, Wang RH et al. Orphan receptor TR3 enhances p53 transactivation and represses DNA double-strand break repair in hepatoma cells under ionizing radiation. Mol Endocrinol 2011; 25: 1337-1350.

23. Zhang S, Yajima H, Huynh H, Zheng J, Callen E, Chen HT et al. Congenital bone marrow failure in DNA-PKcs mutant mice associated with deficiencies in DNA repair. $J$ Cell Biol 2011; 193: 295-305.

24. Allalunis-Turner MJ, Lintott LG, Barron GM, Day RS 3rd, Lees-Miller SP. Lack of correlation between DNA-dependent protein kinase activity and tumor cell radiosensitivity. Cancer Res 1995; 55: 5200-5202.

25. Langland GT, Yannone SM, Langland RA, Nakao A, Guan Y, Long SB et al. Radiosensitivity profiles from a panel of ovarian cancer cell lines exhibiting genetic alterations in p53 and disparate DNA-dependent protein kinase activities. Oncol Rep 2010; 23: $1021-1026$.

26. Jongmans W, Artuso M, Vuillaume M, Brésil H, Jackson SP, Hall J. The role of Ataxia telangiectasia and the DNA-dependent protein kinase in the p53-mediated cellular response to ionising radiation. Oncogene 1996; 13: 1133-1138.

27. Feki A, Jefford CE, Berardi P, Wu JY, Cartier L, Krause KH et al. BARD1 induces apoptosis by catalysing phosphorylation of p53 by DNA-damage response kinase. Oncogene 2005; 24: $3726-3736$

28. Hill $R$, Madureira PA, Waisman DM, Lee PW. DNA-PK p21WAF1/CIP1 promoter blocks transcription resulting in cell death. Oncotarget 2011; 2: 1094-1108.

29. Li Y, Zhao Y, Jiang R, Xu Y, Ling M, Pang Y et al. DNA-PKcs-mediated stabilization of p53 by JNK2 is involved in arsenite-induced DNA damage and apoptosis in human embryo lung fibroblast cells. Toxicol Lett 2012; 210: 302-310.

30. Nacht M, Strasser A, Chan YR, Harris AW, Schlissel M, Bronson RT et al. Mutations in the p53 and SCID genes cooperate in tumorigenesis. Genes Dev 1996; 10: 2055-2066.

31. Kiaris $\mathrm{H}$, Chatzistamou I, Trimis G, Frangou-Plemmenou M, Pafiti-Kondi A, Kalofoutis A Evidence for nonautonomous effect of p53 tumor suppressor in carcinogenesis. Cancer Res 2005; 65: 1627-1630

32. Andersson $S$, Davis DL, Dahlbäck $H$, Jörnvall $H$, Russell DW. Cloning, structure, and expression of the mitochondrial cytochrome P-450 sterol 26-hydroxylase, a bile acid biosynthetic enzyme. J Biol Chem 1989; 264: 8222-8229.

(c) (i) $(9)$ Cell Death and Disease is an open-access journal published by Nature Publishing Group. This work is licensed under the Creative Commons Attribution-NonCommercial-No Derivative Works 3.0 Unported License. To view a copy of this license, visit http://creativecommons.org/licenses/by-nc-nd/3.0/ 